\title{
Case Study on Critical Success Factors of Running Scrum*
}

\author{
Jiangping Wan ${ }^{1,2}$ Yahui Zhu ${ }^{1}$ Ming Zeng ${ }^{1}$ \\ ${ }^{1}$ School of Business Administration, South China University of Technology, Guangzhou, China; ${ }^{2}$ Institute of Emerging Industrializa- \\ tion Development, South China University of Technology, Guangzhou, China. \\ Email: scutwjp@126.com, zhuyahui0819@qq.com,987541400@qq.com
}

Received January $8^{\text {th }}, 2013$; revised February $6^{\text {th }}, 2013$; accepted February $14^{\text {th }}, 2013$

\begin{abstract}
Agile development 12 principles, and adaptive project management life cycle model are applied to case study of J group, the critical success factors of running Scrum are identified as follows: 1) explicit the process of project management and a self-managing group with Scrum; 2) professional agile development and release capability; 3) building learning organization. J group as a pioneer Scrum agile software development practices, realizes the productivity of significant promotion and cost reduction, accelerates the product to the market, improves customer satisfaction and achieves a more transparent development process and higher predictive capability. The study aims to improve the success rate of the running Scrum.
\end{abstract}

Keywords: Agile Software Development; Scrum; Critical Success Factors; Case Study

\section{Introduction}

Agile software development encourages the formation of collaborative and self-organization teams that will have a huge competitive advantage over those who hold the view that a software development organization is nothing more than a pile of twisty little people all alike. A gelled software team is the most powerful software development force there is. The Agile Manifesto is as follows: 1) Individuals and interactions over processes and tools. 2) Working software over comprehensive documentation. 3) Customer collaboration over contract negotiation. 4) Responding to change over following a plan. Twelve principles underlie the Agile Manifesto, including 1) Our highest priority is to satisfy the customer through early and continuous delivery of valuable software. 2) Welcome changing requirements, even late in development. Agile processes harness change for the customer's competitive advantage. 3) Deliver working software frequently, from a couple of weeks to a couple of months, with a preference to the shorter timescale. 4) Business people and developers must work together daily throughout the project. 5) Build projects around motivated individuals. Give them the environment and support they need, and trust them to get the job done. 6) The most efficient and effective method of conveying information to and within a development team is face-to-face conversation. 7) Working software is the primary measure of progress. 8)

${ }^{*}$ This research was supported by Key Project of Guangdong Province Education Office. (06JDXM63002), NSF of China (70471091), and QualiPSo (IST-FP6-IP-034763).
Agile processes promote sustainable development. 9) The sponsors, developers, and users should be able to maintain a constant pace indefinitely. 10) Continuous attention to technical excellence and good design enhances agility. 11) Simplicity. 12) The best architectures, requirements, and designs emerge from self-organizing teams $[1,2]$.

J group was found in 1980, which had created the first Electronic Medical Record (EMR) in 1985, its headquarter was located in Toronto, Canada. It has branch firms in American, France, India and China. Shenzhen, as a main branch of the research and development headquarter, providing technical and business support for the whole group. J group is committed to the field of agile software development, especially in running Scrum. J group has an agile development team, including many of professional consultants, all of them has more than 10 years' work experience in IT companies and the insightful understanding of software development, project management and other related fields.

This paper is organized in the following: Section 2 is literature review, including Scrum framework, ten principles of knowledge creation in open source software community and particular in resource capability arbitration among multiple Scrum teams. Section 3 is research design. Section 4 identifies critical success factors of running Scrum. Section 5 is conclusions.

\section{Literature Review}

Scrum is an innovative approach to getting work done. Scrum is an agile framework for completing complex 
projects. Scrum originally was formalized for software development projects, but works well for any complex, innovative scope of work. The possibilities are endless. The Scrum framework illustrated in Figure 1 [3].

There are several key roles in Scrum framework: 1) Stakeholders: the mission owners possess the idea about why to build, what to build, and how processes should be. 2) Product owner: the product development owner, closely working with stakeholders, creates a prioritized wish list-story-called a Product Backlog. 3) Scrum Master: the facilitator, closely working with product owner, makes sure the stories in the product backlog will successfully delivered as workable sub-products. 4) Scrum team: the developers, closely working with Scrum Master, deliver workable sub-products according to the product backlog.

Scrum Master with the team invites the product owner to debrief the stories in product backlog. Scrum Master leads a Sprint Planning with the team to disassemble the story into tasks, a Sprint Backlog. It is a Scrum team effort to decide how to implement and who should do the tasks. Daily-Scrum is a group meeting to discuss the progress of task implementation and technical issues. Scrum Master keeps the team focused on its goal. At the end of the sprint, the process of development, the work should be potentially shippable, as in ready to hand to stakeholders. The sprint ends with a sprint review and retrospective. As the next sprint begins, the team chooses another chunk of the product backlog and begins working again. The cycle repeats until enough items in the product backlog have been completed, the budget is depleted, or a deadline arrives. Which of these milestones marks the end of the work is entirely specific to the project. No matter which impetus stops work, Scrum ensures that the most valuable work has been completed when the project ends.

J. P. Wan and R. T. Wang have discussed agile software process improvement in $\mathrm{P}$ company with their description of process management in current level and analysis of problems, design the P Company critical success factors model in organizational culture, systems, products, customers, markets, leadership, technology and other key dimensions, which is verified with questionnaire in $\mathrm{P}$ company. They also apply knowledge creation theory to analyze the open source software community of successful application of the typical agile software method, propose ten principles of knowledge creation in open source software community: self-organizing, code sharing, adaptation, usability, sustention, talent, interaction, collaboration, happiness, and democracy [4].

Rich C. Lee researched the following questions: 1) What are the critical factors of success team communication in running Scrum? 2) How Scrum Master alleviates the challenge when team members lack of skills to complete the assigned task? 3) Should Scrum Masters exchange resources for specific skill required tasks? 4) What are the criterions of resource exchange among Scrum teams? [5].

\section{Research Design}

The resolution of the running Scrum is put forward with the deep analyzing of the various factors in J group's agile project and its challenges, resolution for the running Scrum, including organization breakdown structure, explicit the project management process, the self-managing of Scrum team, professional agile development and release, expending Scrum management, building learning organization, and then analysis the effects of running Scrum to confirm successful, including productive efficiency, teamwork, adaptability, responsibility, cooperation ability, then the key processes of running Scrum, including determinate phase, planning phase, start-up phase, supervision and control phase, decided to start the iteration phase and closeout phase, finally the critical success factors in running Scrum of J group are identified. The framework of research is illustrated in Figure 2.

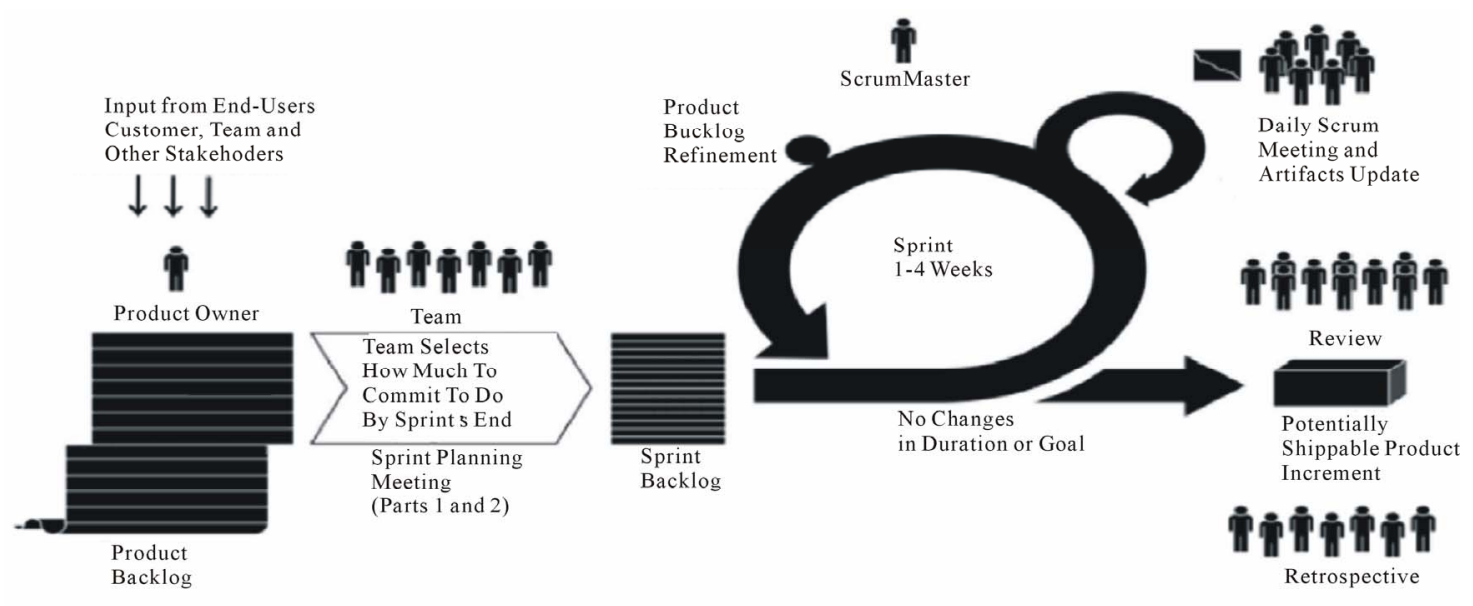

Figure 1. Scrum framework. 


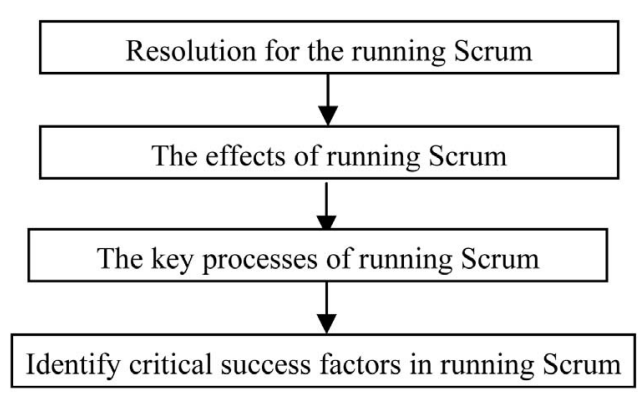

Figure 2. Research framework.

\section{Identify Critical Success Factors of Running Scrum}

\subsection{Overview of Running Scrum in J Group}

The decision-making committee of J group had a kick-off meeting of the Scrum project at March 15, 2006, and set up the Scrum transformed community, including the experienced staffs of the engineering and development, the vice presidents of the product management, marketing, sales, operations and HR department, and the leaders of the QA department, development, architecture, interaction design and database. About 15 people joined the community, in which the time of each one involved ranges from 8 to 24 months, it depends on their roles in the group and the periods of time they have promised. As the transformation affected all sections of the group, so the members we selected should on behalf of almost the entire group. The community has a two-hour meeting per week.

\subsection{Solutions of Running Scrum in J Group}

\subsubsection{Organization Breakdown Structure for Running Scrum}

The Scrum team of $\mathrm{J}$ group consists of Scrum Master, product leader and team. Scrum Master, customers and management layer determine the candidate of the product manager together. Scrum Master is responsible for teaching the product manager how to work, which should learn to run the Scrum in order to optimize the product development (Figure 3).

\subsubsection{Explicit the Project Management Process}

For the success of the project, we should balance the project management process with the produce-oriented process. The same process should be selectively applied to different projects, and the rational using should be made depend on both the current situation and the difference of the running project.

\subsubsection{The Self-Managing of Scrum Team}

As the Scrum methods had all the inherent flexibility of the agile development, we could have the project team

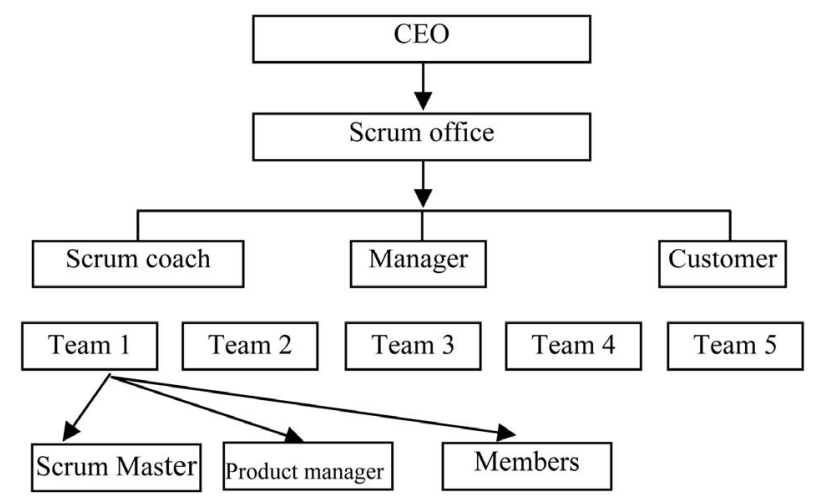

Figure 3. The breakdown structure of $\mathrm{J}$ group.

customized according to the different requirement. A few members of the agile team collected and distributed the key information before the daily team meeting. A simple dashboard for the other members is established, so that all the team members can quickly share their work in the daily meeting. No matter where are they, all the people can work properly.

\subsubsection{Professional Agile Development and Release}

$\mathrm{J}$ group follows the "synchronizations and periodic stabilizations" strategy in development and the releasing of the new product [6]. It means all the work can be carried out paralleled and synchronized, in which many of the steps are incremental progressive and paralleled carried out, and need coordination and running in automated. The unique of the $\mathrm{J}$ group is the ways of the running, which can support the incremental evolution of the product characteristics' marketing strategy, and each team focus on finishing work as soon as possible, as well as providing a large number of customized products.

J group's agile team usually adopts a mixed type development. Using the traditional sequential steps at the beginning, once the first stage of the product characteristics finished, the team will turn to a frequent-build process, in order to keep synchronizations and periodic stabilizations in the evolution. The construction will be taken specific measures that carrying out daily synchronized debugging, providing customizes products and multiple platform version, centralized office, using a common language and the continuing testing.

\subsubsection{Expending Scrum Management}

Scrum development team usually has no more than 7 - 10 members. This scale can finish a lot of tasks, especially in permitting and encouraging the use of agile development process. However, some special projects need the larger team.

$\mathrm{J}$ group should overcome the challenges of running Scrum in large and multi-team project, including expanding more product managers, finishing the backlog of 
the large-scale products, the coordination between different teams, the synchronization and expansion of the Sprint planning meeting.

Product managers play a crucial role in the running Scrum. For a small-size team, their internal task is to participate in the Sprint planning meeting, review Sprint meeting and daily meeting, manage the product backlog, solve the team problems and always keep online during the Sprint. For the large-scale and multiple teams, their external task contains requirement analysis, carrying out the users investigate, participating in trade fairs, managing the expectations of the project stakeholders, providing the priority of the product backlog, deciding the prices, making the medium-and-long-term product strategy, observing the market trends and analyzing the competition.

The multi-team project has different version, J group must expand the product managers. Many large-scale project teams select commercial agile tools to support the backlog. All the tools should meet two principles as follows: 1) if there is only one product, it should be only one backlog; 2) the scale of the backlog should be reasonable.

When more than one team expanding, the coordination is very important. A common practice is Scrum of Scrum, these meeting allow teams to discuss their work, especially in crossing and integrated data.

When more than one team involves in the same Scrum project, each team should manage its own Sprint. Overlapping Sprint would lead to many problems, because it is impossible that all the teams finish their tasks at a common time, and it is too difficult to deploy and provide a complete system's feedback. Therefore, synchronized Sprint is necessary. It allows all teams start and end Sprint in a day or two, and the length of Sprint need not to be the exactly the same.

\subsubsection{Building Learning Organization}

Even if an operation does well for A enterprise, it is usually not suitable for B enterprise. Only through constant self-reflection, feedback and sharing can enterprises improve themselves. It includes systematic review and learning, standardizing measurement and timely feedback, customized consultant supervision and strengthen the communication among different teams.

Either the different departments of J group or the different teams of the same product, the project experience and achievements of each team are different. At the end of the project, the team should finish the documents analysis, which has a brief description of the development and testing, and summing up experience and lessons help the team to avoid the same mistake in next project. In addition, the documents also conclude team members, product, quality description, progress and process, they are very important for sharing resources and experiences.
Scrum team leaders adopt some metrics to track and analyze the group. Senior managers will use metric data to estimate resource requirements, schedule planning and the feedback of the stability and performance of the project. In general, these metrics include quality metrics; the number of the defects and their fixed rate; defect analysis report; defect rate per thousand lines; customers' satisfaction and feedback.

"Systematic review and learning" and "Standardizing measurement and timely feedback" are the internal selfreflection of $\mathrm{J}$ group. Learning from external customers is also important. J group adopts a customized consultant supervision, which means extracting a consultant from the main cooperators to participate and supervise the crucial projects. Enterprises should provide a variety of channels and opportunities to customers to feedback information, and must have a customer service department to analysis and classify the data to improve the data sources.

$\mathrm{J}$ group establishes a series of communication mechanisms for cross product teams so that all the team could share components and standardize characteristics. Not only in reusing the design and code, but also each team committed to standard components and architecture.

\subsection{Performance of Running Scrum in $\mathrm{J}$ Group}

$\mathrm{J}$ group spent 8 months in investigating 50 Scrum development projects in 2011, more than 600 people involved, the number of the teams adopting Scrum was rapid increasing. These projects are engaged in the scheduler, registration, billing, and service for millions of customers and other incremental projects. Everyone who using Scrum in J group once a quarter (including the owner of the product, developer, Scrum Master and managers) was investigated, and make a comparison with the previous development (Table 1).

\subsection{Identify the Critical Success Factors of Running Scrum}

With the different phases of running Scrum project case study, particularly in running J group's Scrum project, the key processes of the running Scrum were explicitly summarized in Table 2.

Table 1. The effect of the running scrum.

\begin{tabular}{cccc}
\hline & Increase greatly & Not change & Decrease \\
\hline Productive efficiency & $68 \%$ & $27 \%$ & $5 \%$ \\
Teamwork & $52 \%$ & $39 \%$ & $9 \%$ \\
Adaptability & $63 \%$ & $33 \%$ & $4 \%$ \\
Responsibility & $62 \%$ & $32 \%$ & $6 \%$ \\
Cooperation ability & $81 \%$ & $18 \%$ & $1 \%$ \\
\hline
\end{tabular}


Table 2. The key processes of running scrum.

\begin{tabular}{|c|c|c|}
\hline 1. Determinate phase & 2. Planning phase & 3. Start-up phase \\
\hline $\begin{array}{l}\text { 1. Develop the real requirements of } \\
\text { customers; } \\
\text { 2. Write a one page project description; } \\
\text { 3. Recode the requirement of customers; } \\
\text { 4. Gain the senior managers' permission to } \\
\text { run the project; } \\
\text { 5. Discuss how to meet the requirements } \\
\text { with the customers. }\end{array}$ & $\begin{array}{l}\text { 1. Define all the work of the project; } \\
\text { 2. Establish the schedule of initial project; } \\
\text { 3. Assess the time required to complete the project; } \\
\text { 4. Analyze and adjust the project schedule; } \\
\text { 5. Assess the resource required to complete the project; } \\
\text { 6. Write the risk management plan; } \\
\text { 7. Assess the whole cost of the project; } \\
\text { 8. Record the project plan; } \\
\text { 9. Sort the work in chronological order; } \\
\text { 10. Get the senior management's permission to start the } \\
\text { project. }\end{array}$ & $\begin{array}{l}\text { 1. Recruit project manager; } \\
\text { 2. Build the scope change management } \\
\text { process; } \\
\text { 3. Recruit the project team members; } \\
\text { 4. Manage the team communication; } \\
\text { 5. Write the descriptive document } \\
\text { of project; } \\
\text { 6. Determine the schedule; } \\
\text { 7. Build the team operating rules; } \\
\text { 8. Write the work package. }\end{array}$ \\
\hline 4. Supervision and control phase & 5. Decided to start the iteration phase & 6. Closeout phase \\
\hline $\begin{array}{l}\text { 1. Build the running and reporting system; } \\
\text { 2. Report the schedule; } \\
\text { 3. Supervise the running; } \\
\text { 4. Deal with the request of scope change; } \\
\text { 5. Supervise the risks; } \\
\text { 6. Identify and solve the problems. }\end{array}$ & $\begin{array}{l}\text { 1. Decision-making process for customer management; } \\
\text { 2. Customers must be fully involved in this process; } \\
\text { 3. The atmosphere must be complete open and honest; } \\
\text { 4. Determination must base on the expected commercial } \\
\text { value; } \\
\text { 5. Solution must be formed according to the project's } \\
\text { goal. }\end{array}$ & $\begin{array}{l}\text { 1. Get the confirmation of the customer; } \\
\text { 2. Prepare for the deliverables } \\
\text { and installations. } \\
\text { 3. Write the closeout report; } \\
\text { 4. Start the audit of the running. }\end{array}$ \\
\hline
\end{tabular}

Questionnaire survey was mainly carried in February 2012 to March 2012 in shenzhen area between five companies with the e-mail. A total of send an email was 60 , and a total recovery is effective questionnaire was 40 . Effective recovery is 66\%. Tables 3-7 are respondent and survey unit, survey industry, customer party cooperation time for the visited enterprise, agile software development history for the visited enterprise and the role of distribution in project respectively.

The respondents are engaged mainly in information and IT industry, and service scale, the project cycle and individual participation in Scrum experience are more average. Respondents, which include Scrum project management four people, and a lot of really relate to a specific Scrum of team 22 engineers. It makes the data more convincing.

With case study on the key processes of running Scrum and referring the 12 principles of agile development and adaptive project management life cycle theory and model, in addition to survey, the critical success factors of running Scrum are identified as follows: 1) Explicit processes of project management and a self-managing group with Scrum. 2) Professional agile development and release capacity (work synchronizations and periodic stabilizations debug everyday, customize product and have lots of versions of product, work together, use the same development language), and expended Scrum management (expended the manager of the product, finish a large products backlog of work, work and coordination each other, expend the Sprint meeting). 3) Building learning organization (System analysis and studies, measure standardization and feedback the thoughts, use customer adviser and improve the product, strengthen the communization and sharing with different team).
Table 3. Respondent and survey unit.

\begin{tabular}{cc}
\hline Enterprise survey & Interview \\
\hline P Company & $\sqrt{ }$ \\
I R\&D Division & $\sqrt{ }$ \\
Y IT Service, Division & $\sqrt{ }$ \\
C centre of network & $\sqrt{ }$ \\
D Company & $\sqrt{ }$ \\
Effective recovery 66\% & \\
\hline
\end{tabular}

Table 4. Survey industry.

\begin{tabular}{cc}
\hline Industry & $\%$ \\
\hline IT service & $49.5 \%$ \\
Electronic and information & $18.8 \%$ \\
Financial securities & $17.8 \%$ \\
Medical services & $13.9 \%$ \\
\hline
\end{tabular}

Table 5. Customer party cooperation time for the visited enterprise.

\begin{tabular}{cc}
\hline Year & $\%$ \\
\hline$<1$ & $22.9 \%$ \\
$1-3$ & $45.7 \%$ \\
$3-5$ & $11.4 \%$ \\
$>5$ & $20 \%$ \\
\hline
\end{tabular}

Table 6. Agile software development history for the visited enterprise.

\begin{tabular}{cc}
\hline Year & $\%$ \\
\hline $1-3$ & $22.9 \%$ \\
$3-5$ & $57.1 \%$ \\
$>5$ & $20 \%$ \\
\hline
\end{tabular}


Table 7. The role of distribution in project.

\begin{tabular}{cc}
\hline Role & $\%$ \\
\hline Scrum Master & $11.4 \%$ \\
Product principal & $62.9 \%$ \\
Developer & $8.6 \%$ \\
Designer & $2.9 \%$ \\
Tester \& others & $14.2 \%$ \\
\hline
\end{tabular}

\section{Conclusion}

With case study on J group's running Scrum, it is found that enterprise should select and apply 12 principles of agile development reasonably, and improve the agile project management and support project operation according to adaptive project management life cycle model. We try to illustrate the design elements of the project management processes and the crucial success factors of running Scrum's transformation. Scrum's transformation happens in different departments, different places and different time, if there is no a clear model or standardized process (Adaptive project management life cycle) to assess the regular assessment, the success will be impossible. It will provide a successful reference for other enterprises.

\section{Acknowledgements}

Thanks for helpful discussion with Mrs. Panpan Wang, Mr. Zhou Zhijun, Mr. Jiangzhang Li and Mr. Wang Shu- wen.

\section{REFERENCES}

[1] K. Beck, M. Beedle, et al., "Manifesto for Agile Software Development,” 2009. http://agilemanifesto.org/

[2] L. Williams, "What Agile Teams Think of Agile Principles Even after Almost a Dozen Years, They Still Deliver Solid Guidance for Software Development Teams and Their Projects," Communications of ACM, Vol. 55, No. 4, 2012, pp. 71-76. doi:10.1145/2133806.2133823

[3] P. Deemer, G. Benefield, C. Larman and B. Vodde, “The SCRUM Primer,” 2013.

http://www.brianidavidson.com/agile/docs/scrumprimer1 21.pdf

[4] J. P. Wan and R. T. Wang, "Empirical Research on Critical Success Factors of Agile Software Process Improvement," Journal of Software Engineering and Applications, Vol. 3, No. 12, 2010, pp. 1131-1140. doi:10.4236/jsea.2010.312132

[5] R. C. Lee, "The Success Factors of Running Scrum: A Qualitative Perspective,” Journal of Software Engineering and Applications, Vol. 5, No. 6, 2012, pp. 367-374. doi:10.4236/jsea.2012.56043

[6] M. A. Cusumano and R. W. Selby, "Microsoft Secrets: How the World's Most Powerful Software Company Creates Technology, Shapes Markets and Manages People," Free Press, New York, 1995. 